Revisão Sobre a Relação Estrutura-Função das Substâncias Húmicas e a sua Regulação do Metabolismo Oxidativo em Plantas

\author{
García, A. C.;*Castro, T. A. V. T.; Berbara, R. L. L.; Tavares, O. C. H.; Elias, \\ S. S.; Amaral Sobrinho, N. M. B.; Pereira, M. G.; Zonta E.
}

Rev. Virtual Quim., 2019, 11 (3), 754-770. Data de publicação na Web: 21 de maio de 2019

http://rvq.sbq.org.br

\title{
Critical Review About Structure-Functions Relationship for Humic Substances Interactions with Plant Oxidative Metabolism
}

Abstract: The understanding of humic substances (HS) chemistry in soil science faces new challenges at present. Theories alternative to humification (HS formation process) have been presented to scientific community propagating uncertainty about the existence of these compounds as a structural entity located in the soil. In this review, we aim to show in a compressible manner that HS have a structural pattern independent of its origin, which allows us the characterization by means of techniques common to other groups of compounds $\left({ }^{13} \mathrm{C} N M R \mathrm{CP} / \mathrm{MAS}\right)$. These characteristics (C-aliphatic, $\mathrm{C}$ aromatic, carboxyl, carbonyl) allow the obtaining and quantification of HS properties (aromaticity, aliphaticity, hydrophobicity, recalcitrance) that define different functions in the soil (plant bioactivity). The preservation of the structureproperty-function relationship of HS qualifies them as a chemical compounds groups that are formed in the soil and are widely distributed in nature. The relevance of the supramolecularity concept to explain chemical and organizational characteristics of the humic structure, as well as, the use of spectroscopic techniques combined with chemometrics to understand the complex behavior of HS and its various functions is highlighted in this review.

Keywords: Humic acids; spectroscopy; Chemometric; oxidative stress.

\section{Resumo}

O entendimento da química das substâncias húmicas ( $\mathrm{SHs}$ ) na ciência do solo enfrenta hoje novos desafios. Teorias alternativas à humificação (processo de formação das $\mathrm{SH}$ ) têm sido apresentadas à comunidade científica gerando questionamentos sobre a existência destes compostos como uma entidade estrutural presente no solo. Esta revisão tem como objetivo mostrar de forma compreensível que as SHs possuem um padrão estrutural independente da fonte de origem, que permite a caracterização por meio de técnicas comuns a outros grupos de compostos $\left({ }^{13} \mathrm{C} N \mathrm{NR} \mathrm{CP} / \mathrm{MAS}\right)$. As características que as SHs apresentam (C-alifáticos, C-aromáticos, carboxilas, carbonilas) permitem a obtenção e quantificação de propriedades (aromaticidade, alifaticidade, hidrofobicidade, recalcitrância) que definem as diferentes funções que as mesmas exercem no solo (bioatividade em plantas). A preservação da relação estrutura-propriedade-função das $\mathrm{SH}$ as qualifica como compostos químicos que são formados no solo e que estão amplamente distribuídos na natureza. Destaca-se nesta revisão a importância do conceito de supramolecularidade para explicar as características químicas e organizacionais da estrutura húmica e o uso de técnicas espectroscópicas aliadas à quimiometria para entender o comportamento complexo das SHs e suas diversas funções.

Palavras-chave: Ácidos húmicos; espectroscopia; quimiometria; estresse oxidativo.

\footnotetext{
* Universidade Federal Rural do Rio de Janeiro, Instituto de Agronomia, Laboratório de Química Biológica do Solo, Departamento de Solo, CEP 23890-000, Rio de Janeiro-RJ, Brasil.

Mcg.andres@gmail.com DOI: $\underline{10.21577 / 1984-6835.20190055}$
} 


\title{
Revisão Sobre a Relação Estrutura-Função das Substâncias Húmicas e a sua Regulação do Metabolismo Oxidativo em Plantas
}

\author{
Andrés C. García, ${ }^{\mathrm{a}, *}$ Tadeu A. van Tol de Castro, ${ }^{\mathrm{a}}$ Ricardo L. L. Berbara, ${ }^{a}$ \\ Orlando C. H. Tavares, ${ }^{a}$ Sael S. Elias, ${ }^{\text {a }}$ Nelson M. B. de Amaral Sobrinho, ${ }^{b}$ \\ Marcos G. Pereira, ${ }^{\mathrm{c}}$ Everaldo Zonta ${ }^{\mathrm{d}}$ \\ a Universidade Federal Rural do Rio de Janeiro, Laboratório de Química Biológica do Solo, \\ Departamento de Solo, CEP 23890-000, Rio de Janeiro-RJ, Brasil. \\ ${ }^{b}$ Universidade Federal Rural do Rio de Janeiro, Laboratório de Química do Solo, \\ CEP 23890-000, Rio de Janeiro-RJ, Brasil. \\ c Universidade Federal Rural do Rio de Janeiro, Laboratório de Gênese e Classificação de Solo, \\ CEP 23890-000, Rio de Janeiro-RJ, Brasil \\ ${ }^{d}$ Universidade Federal Rural do Rio de Janeiro, Laboratório de Fertilidade do Solo, \\ Departamento de Solo, CEP 23890-000, Rio de Janeiro-RJ, Brasil \\ *cg.andres@gmail.com
}

Recebido em 24 de agosto de 2018. Aceito para publicação em 17 de abril de 2019

1. Introdução

2. Padrão Estrutural das Substâncias Húmicas

3. Efeitos das Substâncias Húmicas na Regulação da Homeostase REDOX das Plantas

4. Relação da Estrutura das Substâncias Húmicas com as suas Funções em Nível Radicular

5. Conclusões

\section{Introdução}

A partir da publicação do livro de Wallerius (1761), ${ }^{1}$ a química do húmus se estabelece como uma área de pesquisa dentro da química agrária e desde então se considera a presença de húmus no solo como o resultado da decomposição de detritos de plantas. Posteriormente os trabalhos sobre a química do húmus realizados por Waksman (1936), ${ }^{2}$
Kononova (1961-1966), ${ }^{3,4}$ Russell (1973), ${ }^{5}$ Orlov $(1985)^{6}$ direcionaram as pesquisas para entender o papel deste grupo de compostos no solo e a sua relação com a nutrição das plantas.

Trabalhos mais avançados sobre a química das substâncias húmicas (SHs) foram desenvolvidos por Kononova $(1961,1966),{ }^{3,4}$ Stevenson $(1982,1994),{ }^{7,8}$ Schultene Schnitzer (1993). ${ }^{9}$ Estes autores propuseram modelos estruturais para as $\mathrm{SH}$ baseados nas 
capacidades tecnológicas e analíticas daquele momento (década de 60 a 90) e estabeleceram as bases para o entendimento das SHs como macromoléculas com um comportamento de polieletrólitos no solo.

$\mathrm{Na}$ atualidade, com os avanços e o poder das técnicas analíticas, outros autores como Hayes et al. (2009) $)^{10}$ e Piccolo et al. (2000$2012)^{11,12}$ redirecionaram suas pesquisas para o entendimento estrutural das $\mathrm{SH}$ e suas frações representativas, como no caso da humina (até esse momento reconhecida como a fração mais estável das SHs). Os trabalhos de Simpson et al. (2007) ${ }^{13}$ mostraram que as huminas, por estarem constituídas por uma mistura complexa de agregados estáveis de biomoléculas e não de matéria humificada, não satisfazia então a definição clássica de $\mathrm{SH}$. Isto foi posteriormente comprovado por García et al. (2016) ${ }^{31}$, onde foi demonstrado que as huminas podiam ser basicamente fragmento de ácidos húmicos (AH) mais fortemente ligados à fração mineral do solo.

Por outro lado, os trabalhos desenvolvidos por Nebbioso et al. $(2011,2012)^{14,15}$ têm apresentado a visão mais atual da estrutura das SH. Os estudos de Piccolo $(2001,2002)^{11,12}$ têm mostrado que as $\mathrm{SHs}$ apresentam uma organização estrutural supramolecular, isto é, as SHs estão organizadas no solo a partir de interações fracas não covalentes do tipo van der Waals, $\pi-\pi, \mathrm{CH}-\pi$ e ligações de hidrogênio. Desta forma, a quantidade de SHs no solo é uma consequência de um equilíbrio entre estruturas húmicas na solução do solo e estruturas húmicas adsorvidas aos minerais do solo mediante atrações hidrofóbicas. ${ }^{16}$

As implicações para este novo paradigma estrutural das SHs são variadas, mas talvez a mais importante esteja relacionada com uma mudança na visão do processo de humificação (processo mediante o qual é atribuída a formação da matéria orgânica (MO) humificada). Assim, a supramolecularidade pressupõe interações hidrofóbicas exclusivas do meio aquoso do solo, que permite um aumento da agregação de estruturas mais estáveis associadas com a fase sólida do solo a partir de um contínuo processo de decomposição da MO fresca. ${ }^{16}$
Os efeitos que as $\mathrm{SH}$ exercem nas plantas são diversos e envolvem diferentes formas de ação. Em plantas, as SHs induzem efeitos no crescimento e desenvolvimento tanto por vias diretas como por vias indiretas. ${ }^{17}$ Os efeitos indiretos estão relacionados com 0 fornecimento de nutrientes; aumento da população microbiana; aumento da capacidade de troca de cátions (CTC) e capacidade tampão de nutrientes no solo; melhoria da estrutura do solo; e fornecimento de compostos específicos (compostos nitrogenados, cadeias carbonadas, fitohormonios) para as plantas. ${ }^{18}$ Já os efeitos diretos estão relacionados com as modificações que as SH são capazes de exercer nos diferentes processos e rotas do metabolismo vegetal. ${ }^{18}$

As propriedades hidrofóbicas das SHs com elevado peso molecular ( $M w)$, têm mostrado estar correlacionadas com o aumento da estabilidade dos agregados nos solos e diminuição dos efeitos de desagregação, ${ }^{19,20} \mathrm{e}$ isto pela capacidade destas estruturas para repelir água, tem possibilitado criar produtos a partir da modificação estrutural das SHs adicionadas ao solo inserindo silício (Si) o que aumenta sua hidrofobicidade e por tanto melhora a estabilidade dos agregados. ${ }^{21} \mathrm{~A}$ presença de quinonas e semiquinonas nas $\mathrm{SH}$ e seu potencial redox, contribuem para a participação como aceptoras de elétrons na respiração microbiana (Geobacter metallireducens). ${ }^{22}$

A heterogeneidade estrutural das $\mathrm{SH}$ e a presença de grupamentos $-\mathrm{OH}$ (hidroxilas), $\mathrm{C}=\mathrm{O}$ (carbonilas) e $-\mathrm{COOH}$ (carboxilas) justificam a capacidade destas substâncias de interagir com íons metálicos. ${ }^{23}$ Os grupamentos funcionais ionizáveis nas $\mathrm{SHs}$ são determinantes na elevada capacidade de troca de cátions (CTC) que estas substâncias possuem, isto porque a dissociação destes grupamentos ionizáveis depende do valor de $\mathrm{pH}$. Dentre as SHs, os AH possuem uma CTC entre $500-1200 \mathrm{cmol} \mathrm{kg}^{-1}$, já os ácidos fúlvicos (AF) possuem valores de $600-1500 \mathrm{cmol} \mathrm{kg}$ $1.24,25$

Os efeitos diretos que as $\mathrm{SH}$ exercem nas plantas ocorre por meio da regulação do seu 
crescimento e desenvolvimento, especificamente e em maior extensão no crescimento radicular. Pela heterogeneidade estrutural das SHs, os efeitos são altamente dependentes da concentração aplicada às plantas, da fonte de origem das $\mathrm{SH}$, do tipo de plantas modelo e do desenho experimental. ${ }^{26-}$ ${ }^{31}$ A capacidade que as $\mathrm{SHs}$ possuem para induzir o crescimento, a morfologia e arquitetura radicular das plantas é relatado na literatura. Está bem estabelecido que várias espécies de plantas como milho (Zeamays); ${ }^{32}$ melão (Cucumis melo L.), alface (Lactuca sativa L.), cebola (Allium cepa L.); ${ }^{33}$ pepino (Cucumissativus L.); ${ }^{34}$ canola; ${ }^{35}$ Arabidopsis (Arabidopsis thaliana) ${ }^{36}$ e arroz (Oryza sativa L.); ${ }^{31,37}$ respondem de forma satisfatória à aplicação via radicular de SHs (Figura 1).

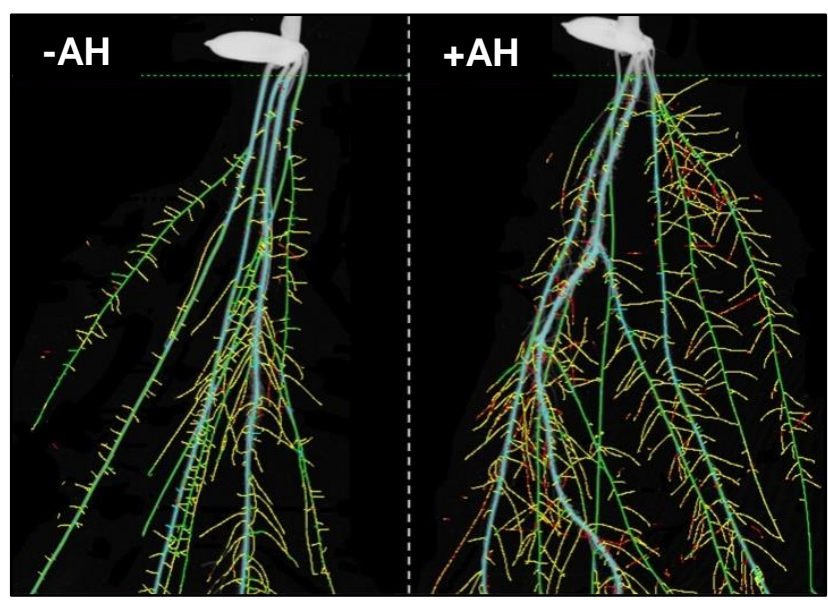

Figura 1. Imagem mostrando o estímulo do crescimento e desenvolvimento de raízes de plantas de arroz sem aplicação de ácido húmico extraído de vermi composto (-AH) e com aplicação de $80 \mathrm{mg}$. L ${ }^{-1}$ de ácido húmico (+AH). Foto: Orlando Carlos Huertas Tavares

O estudo da MO nos solos do Brasil possui elevada importância. Estes são solos sob condições de clima tropical que possuem características ácidas, são intemperizados, com elevada quantidade de minerais cauliníticos e ricos em óxidos de ferro e alumínio. $^{38}$ De maneira geral, a fertilidade destes solos é baixa e, por tanto, a matéria orgânica é essencial pois fornece cargas, nutrientes e preserva o carbono orgânico, melhorando a aptidão dos solos para a agricultura. ${ }^{38}$

No entanto, a química do solo enfrenta talvez o seu maior desafio a respeito da validade dos pressupostos teóricos que explicam as funções da MO no solo. A elevada heterogeneidade estrutural das $\mathrm{SHs}$ e do ambiente vem dificultando o entendimento da formação destas substâncias e gera novas teorias que tentam driblar estes obstáculos. $^{39,40}$ Algumas destas novas propostas expressam desde a negação das SHs e reconhecimento da existência deste grupo de compostos como componente orgânico presente no solo, até o questionamento ao processo de humificação da MO. ${ }^{39,40}$

Esta revisão tem como objetivo elencar alguns argumentos científicos em favor da existência das SHs como entidade estrutural identificável, quantificável e capaz de ser caracterizada, com propriedades que justificam suas funções. Para isto, trazemos à discussão uma série de dados obtidos pelo nosso grupo de pesquisa e alguns resultados da literatura internacional que validam o tema em discussão. Pretendemos ainda trazer uma linguagem simples para explicar um problema complexo, visando a inserção de mais pesquisadores na área das ciências da química do solo que tragam maiores informações sobre a química das $\mathrm{SHs}$. 


\section{Padrão Estrutural das Substâncias Húmicas}

Talvez os pontos mais criticados na pesquisa das $\mathrm{SHs}$ por parte de alguns grupos são, precisamente, a ausência de uma modelo estrutural para as SHs e um mecanismo único que visualize a sua formação. Hoje sabemos que estas exigências não são indispensáveis para entender o papel que as $\mathrm{SH}$ s realizam no meio ambiente. $O$ solo é um sistema altamente heterogêneo, aberto, dinâmico em constante intercâmbio e reposição em curto prazo de seus componentes mais lábeis e a longo prazo submetidos a processos de transformação e evolução como o intemperismo.

No nosso entendimento, qualquer função atribuída à matéria orgânica presente no solo responde às suas características químicas estruturais. Não seria possível então qualquer interpretação entorno à transformação, estabilidade e reatividade do carbono orgânico no solo sem um entendimento estrutural prévio. Assim sendo, processos como a estabilidade da MO que justifica seu acúmulo e estoque, a partir da interação com a fração mineral, encontra as suas explicações a partir de interações químico físicas, como são as ligações covalentes, atrações eletrostáticas e interações hidrofóbicas que os componentes orgânicos estabelecem através de seus grupamentos funcionais com os outros componentes no solo. ${ }^{41} \mathrm{~A}$ baixa acessibilidade dos microrganismos a determinados componentes da fração orgânica do solo se deve às características químicas da MOS que permitem a exclusão do meio aquoso mediante forças de repulsão hidrofóbicas e interações químicas com óxidos, dificultando assim o acesso microbiano para a decomposição. ${ }^{42} \mathrm{~A}$ capacidade da $\mathrm{MO}$ em aumentar a capacidade de troca de cátions e ânions no solo responde à presença de grupamentos ionizáveis de diferente natureza química presentes na estrutura das $\mathrm{SH}$ (aryl-OH, alkyl-OH, $-\mathrm{NH}_{2},-\mathrm{OH}$, $-\mathrm{COOH},-\mathrm{SH}$ ).

Sendo assim, na atualidade, a necessidade de um modelo químico para as $\mathrm{SH}$, que corresponda aos dogmas químicos tradicionais das funções químicas e a um grupo de substâncias em específico, parece uma tarefa sem propósito. Isto porque em um sistema altamente dinâmico como o solo, as reações e transformações que permitem a formação de entidades estruturais húmicas estão em constante balanço termodinâmico. No entanto, mesmo com todos estes pressupostos teóricos, na prática, as $\mathrm{SHs}$ apresentam padrões estruturais que independem da fonte de origem (solo, materiais compostados, etc.).

A Sociedade Internacional de Substâncias Húmicas (SISH) estabelece alguns padrões para as SHs de diferentes fontes de origem, sendo que estas informações podem ser encontradas no site: https://humicsubstances.org. ${ }^{43} \mathrm{~A}$ SISH fornece informações também por outras técnicas analíticas, no entanto, as técnicas ${ }^{13} \mathrm{C}$ RMN $\mathrm{PC} / \mathrm{RAM}$ mostram que os $\mathrm{AH}$, uma fração das $\mathrm{SH}$ s tanto de solos como de outras fontes de origem, apresentam predomínio de C aromáticos, C alifáticos substituídos e não substituídos, assim como $C$ carboxílicos (Figura 2A). Um espectro característico de ${ }^{13} \mathrm{C}$ RMN PC/RAM é mostrado na Figura 2B. 


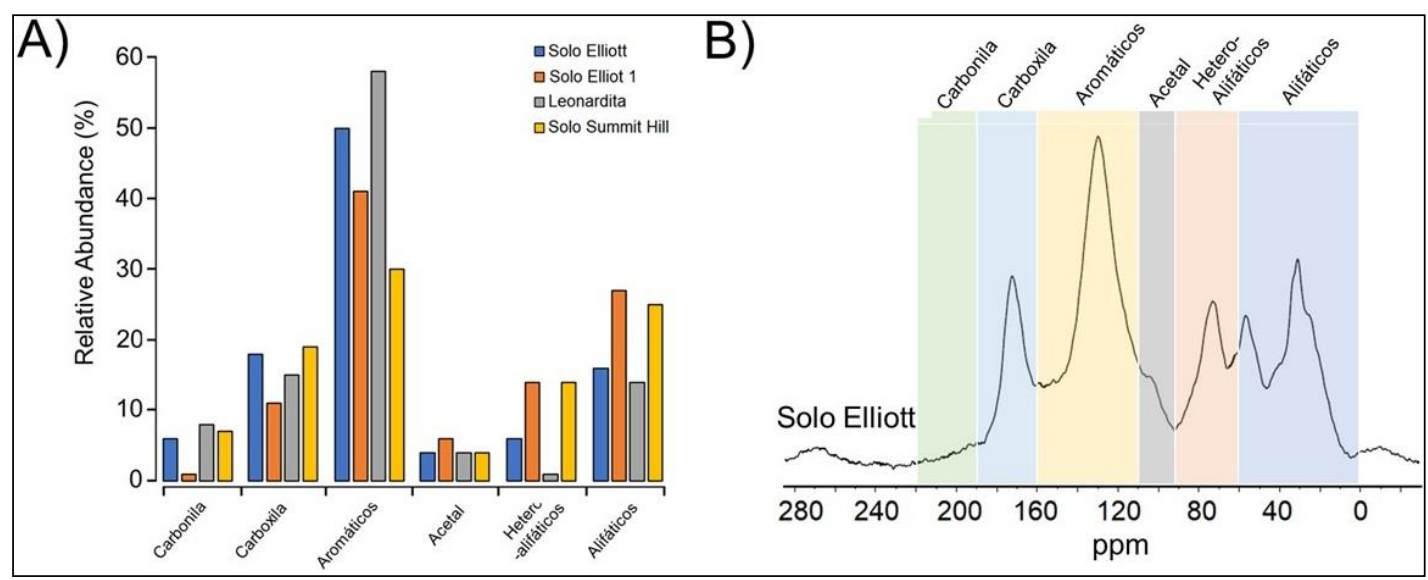

Figura 2. Quantidades relativas de estruturas de $\mathrm{AH}$ nas $\mathrm{SH}$ que propõe a SISH como padrões (A). Espectro ${ }^{13} \mathrm{C} N M R \mathrm{CP} / \mathrm{MAS}$ de $\mathrm{AH}$ de solo Elliott mostrado como padrão na SISH (tomado e modificado das informações disponíveis no site oficial da SISH, https://humic-substances.org). ${ }^{43}$ Solo Elliot: solo fértil presente no estado de Illinois, USA. Solo Summit Hill: solo coletado de Port Hill, Nova Zelanda

A maioria das informações espectrais dos AH disponíveis na literatura coincidem com a presença de estruturas que justificam suas propriedades e funções no solo. A Figura 3 mostra espetros ${ }^{13} \mathrm{C} \quad \mathrm{NMR} \quad \mathrm{CP} / \mathrm{MAS}$ representativo de $\mathrm{AH}$ isolados de solos da floresta nacional de Uncompahgre (área florestal nacional em Colorado, USA). Neste estudo se mostra que a composição estrutural destas frações está fundamentalmente formada por C-alquílicos substituídos e não substituídos, C pertencentes a estruturas de carboidratos, $\mathrm{C}$ aromáticos substituídos e não substituídos, C carboxílicos e carbonílicos (Figura 3).

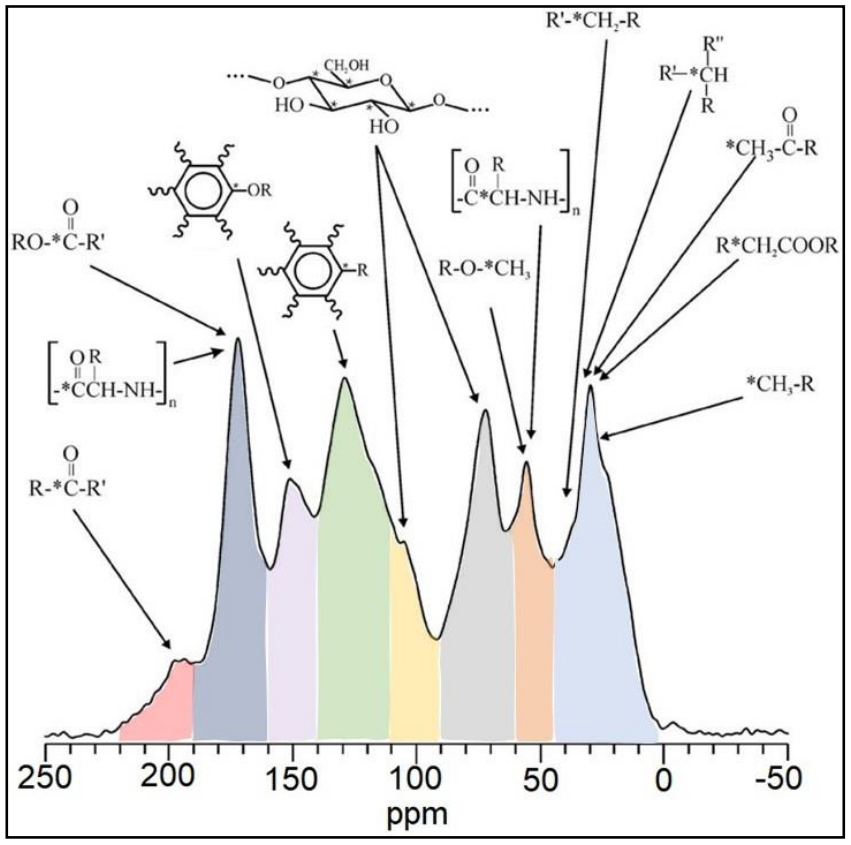

Figura 3. Espectro representativo ${ }^{13} \mathrm{C}$ NMR CP/MAS de $\mathrm{AH}$ isolados de solos isolado de Uncompahgre (tomado e modificado de Keeler et al. 2006) ${ }^{44}$ 
As pesquisas no Laboratório de Química Biológica do Solo (LQBS), têm confirmado estes pressupostos sobre as características estruturais das SHs. Nosso grupo vem trabalhando no isolamento de frações húmicas caraterizadas mediantes técnicas espectroscópicas $\left({ }^{13} \mathrm{C} N \mathrm{NR} \mathrm{CP} / \mathrm{MAS}\right)$ aliadas a análises quimiométricas. É necessário que se entenda que nas condições do solo, onde a reposição de componentes orgânicos é constante e específica às características do ambiente, as quantidades de estruturas que se incorporam à supramolécula húmica muda de acordo com o processo de humificação que ao mesmo tempo depende do caminho termodinâmico e cinético do material fresco depositado.
No entanto, o padrão estrutural da supramolécula húmica se mantém com elevada reprodutibilidade independentemente do tipo de solo (Figura $4 \mathrm{~A})$. Os espectros médios obtidos mediante quimiometria de trinta $\mathrm{AH}$ mostram semelhança estrutural e padrão espectral característicos deste grupo de compostos, independente das características mineralógicas diferentes dos solos avaliados (Figura 4A). Isto comprova que a formação de SH no solo não é definido em toda sua extensão pela proteção ou ambiente mineral do solo, ${ }^{41}$ mas que como componente ativo, a fração mineral pode regular a velocidade e estabilidade das SHs que se formam a través da disposição e reatividade disponível dos fragmentos vegetais e animais na solução do solo.

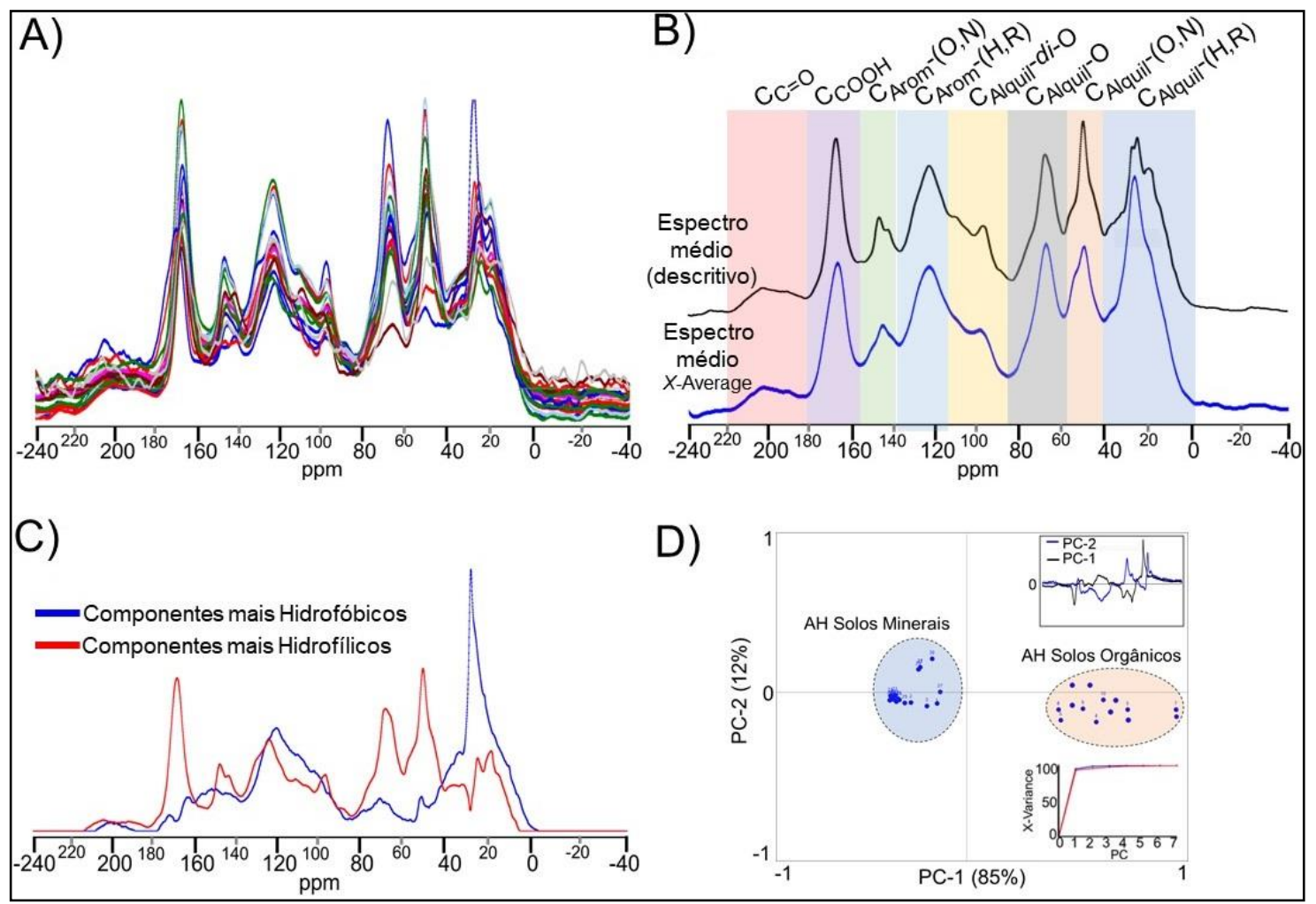

Figura 4. Espectros ${ }^{13} \mathrm{C}$ NMR CP/MAS de trinta (30) $\mathrm{AH}$ isolados de horizontes superficiais de solos orgânicos e solos minerais de diferentes regiões do estado do Rio de Janeiro - Brasil. (A) Espectros normalizados segundo a área (The Unscrambler $X^{\circledR}$ Software CAMO versão 10.3). (B) Espectro ${ }^{13} \mathrm{C}$ NMR CP/MAS médio (linha preta) e espectro médio (linha azul), o espectro médio foi obtido mediante análises descritiva e espectro médio através da análise $\mathrm{X}$ (Reduceaverage) no The Unscrambler $X^{\circledR}$ Software CAMO versão 10.3. (C) Curva de resolução multivariada (CRM) para os 30 espectros ${ }^{13} \mathrm{C}$ NMR CP/MAS. (D) Análise de componentes principais - PCA (scores e loadings) realizadas a partir do carregamento dos espectros. Dados do autor 
Outro aspecto importante é a confirmação de informações que direcionam ao pressuposto teórico sobre o nível organizacional supraestrutural das SHs. A CRM mostra claramente a presença dominante no $\mathrm{AH}$ de dois domínios bem estruturados. Um domínio com características hidrofóbicas composto pelas estruturas Calquil-(H,R) e Carom- $(H, R)$, isto reforça a possibilidade de arranjo supraestrutural das SHs baseado em um domínio polar para a superfície das molécula e um núcleo apolar mais recalcitrante no interior (Figura $4 \mathrm{C}$ ). ${ }^{45} \mathrm{Os}$ scores da PCA confirmam a diferença dos $\mathrm{AH}$ analisados e reafirma que embora os percursos cinético-termodinâmicos para a formação dos AH sejam diferentes, o padrão estrutural é estável, assim os loadings mostram na PC-1 que os domínios hidrofóbicos estão dominando estas diferenças. Isto poderia indicar que a disposição e característica do núcleo hidrofóbico define as interações consecutivas para o crescimento da supramolécula (Figura 4D).

A presença de um padrão estrutural nas $\mathrm{SH}$ do solo independente das características destes, assim como a organização e arranjo destas moléculas em uma supraestrutura húmica estável e termodinamicamente provável, fazem possível despejar as dúvidas sobre a inexistência de uma identidade estrutural húmica no solo, recentemente expostos por grupos de pesquisa que advertem contra a existência de um processo de humificação onde colocam as características estruturais da $\mathrm{MO}$ como um aspecto secundário para explicar suas funções, inclusive a estabilidade do carbono orgânico. $^{39,40}$ Estas escolas confundem os cientistas das ciências do solo, isto porque todo comportamento e funções de qualquer molécula são o resultado das suas características estruturais.

\section{Efeitos das Substâncias Húmicas na Regulação da Homeostase REDOX das Plantas}

Antes do entendimento metabólico e fisiológico em si mesmo, é necessário entender o mecanismo de interação AH-raíz pelo qual as $\mathrm{SHs}$ poderiam induzir à produção de espécies reativas do oxigênio (ERO) em plantas. Os trabalhos desenvolvidos por Asli e Neumann, $(2010)^{46}$ foram talvez os primeiros resultados mostrando que existe uma interação físico-química das $\mathrm{SH}$ s com as raízes de plantas mediante um acúmulo de aglomerados húmicos que pode causar entupimento dos poros e diminuir a condutividade hidráulica sem afetar o crescimento radicular. Olaetzea et al. (2015) ${ }^{47}$ comprovaram que as interações físicoquímicas dos $\mathrm{AH}$ com a superfície das raízes das plantas acarreta uma regulação da tomada de água, expressão de genes de aquaporinas de membranas (PIPS) e da condutividade hidráulica, induzindo uma ação ácido abscícico (ABA)-dependente.

Um modelo para o estudo das interações químicas usando biomembranas mostra que o acúmulo superficial dos $\mathrm{AH}$ acontece inicialmente pela formação de ligações de hidrogênio entre grupamentos polares $\left(C_{\text {Arom- }}\right.$ $\mathrm{O}, \mathrm{C}_{\mathrm{Alqui}} \mathrm{O}$ ) dos $\mathrm{AH}$ e a superfície da membrana. Posteriormente, a adsorção mais rápida ou mais lenta das estruturas húmicas acontece nos sítios defeituosos da superfície da membrana ${ }^{48}$ (Figura 5A). A entrada de fragmentos húmicos utilizando os interstícios na epiderme para o interior das raízes também é confirmada por meio da utilização de $\mathrm{AH}$ marcados com trítio $\left({ }^{3} \mathrm{H}-\mathrm{AH}\right)^{49}$ (Figura $5 B)$.

O grupo de pesquisa do LQBS, tem comprovado que em raízes de plantas de arroz existe uma aglomeração superficial de estruturas húmicas (Figura $5 \mathrm{C}$ ). Os fragmentos húmicos que se aglomeram nas raízes possuem uma presença predominante de estruturas altamente funcionalizadas polares 
( $\mathrm{C}_{\text {Alquil- }} \mathrm{O}, \mathrm{C}_{\mathrm{COOH}}, \mathrm{C}_{\mathrm{C}=\mathrm{O}}$ ) capazes de estabelecer ligações de hidrogênio com a superfície da membrana e uma diminuição de estruturas aromáticas $^{48,50,51}$ (Figura 5B).

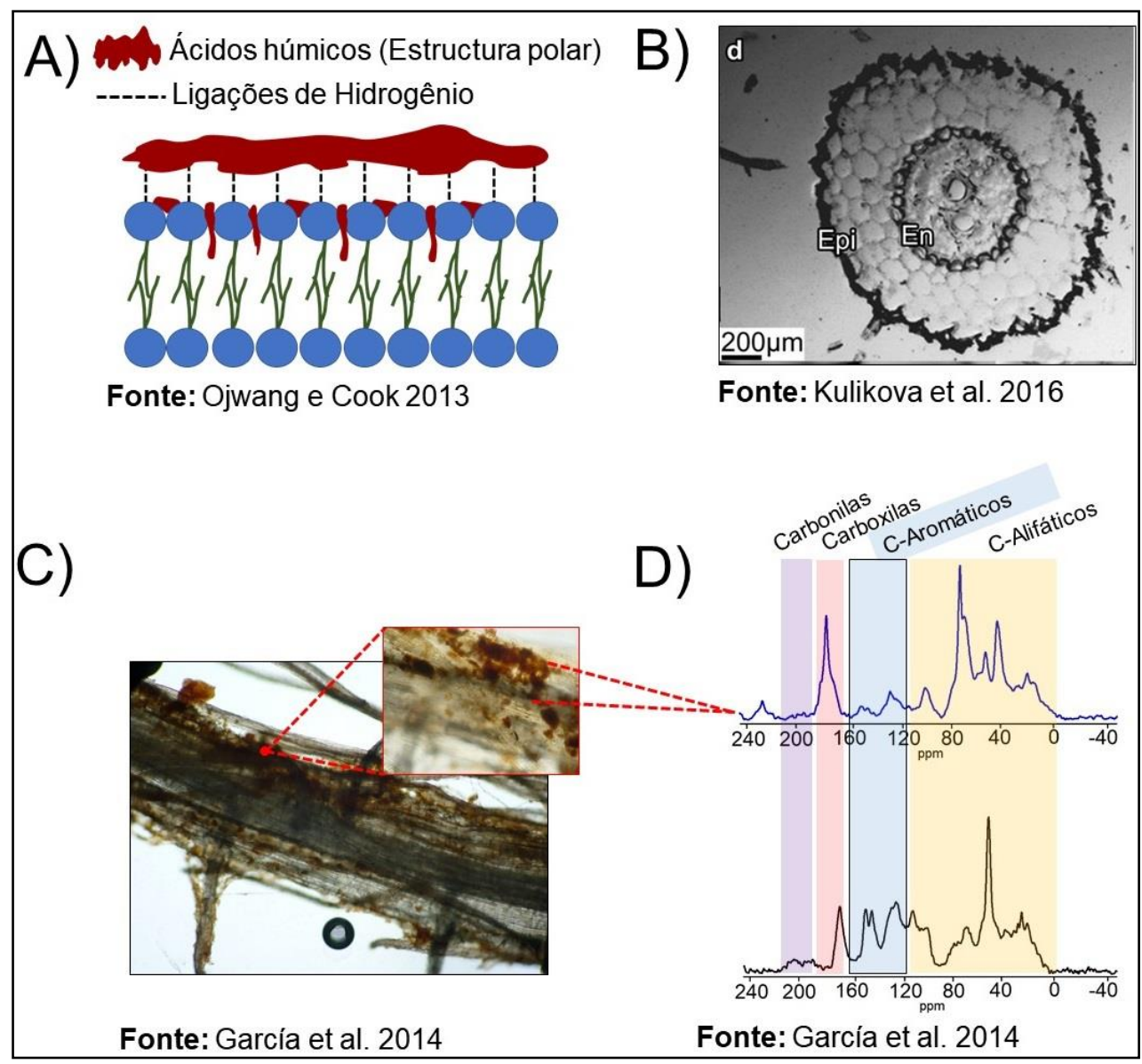

Figura 5. Modos de interação entre ácidos húmicos e raízes de plantas. A) Modelo de aglomeração entre ácidos húmicos e uma biomembrana mostrando as interações iniciais por ligações de hidrogênio na superfície (Ojwangand Cook, 2013). B) Presença de fragmentos húmicos marcados com trítio ( $\left.{ }^{3} \mathrm{H}-\mathrm{AH}\right)$ no interior de raízes de plantas através da epiderme (Epi) (Kulikova et al. 2016). Imagem da aglomeração de AH de vermicomposto na superfície de uma raiz de plantas de arroz (García et al. 2014). D) Espectros ${ }^{13} \mathrm{C}$ RMN PC/RAM dos fragmentos húmicos isolados da superfície radicular, espectro em preto: ácidos húmicos adicionados à solução nutritiva; espectros em azul: fragmentos húmicos extraídos da superfície radicular

Foi observado que existe uma faixa de concentrações dos $\mathrm{AH}$ aplicados que promove esta aglomeração na superfície radicular das plantas induzindo uma regulação do metabolismo redox, especificamente a regulação das espécies reativas de oxigênio (ERO). ${ }^{52}$ Isto é especialmente importante porque as ERO participam como moléculas sinalizadoras nas plantas..$^{53,54,55}$ As ERO regulam a emissão de pelos radiculares através da ação de NADPH oxidases e a ativação de canais de $\mathrm{Ca}^{2+}$ na região apical radicular. ${ }^{56,57,58}$

Estes resultados fornecem novas evidências diante das questões mais importantes sobre o papel que as $\mathrm{SH}$ s realizam nas plantas. A questão menos controversa sobre os efeitos das $\mathrm{SH}$ em plantas é a sua capacidade para estimular o crescimento e desenvolvimento do sistema radicular, ${ }^{59}$ no entanto, a maior controvérsia consiste em explicar quais os mecanismos metabólicos e 
suas vias de sinalização pelo qual estes efeitos ocorrem.

Os resultados têm mostrado que a ação de AH aplicados via radicular nas plantas, aumenta o crescimento das raízes das plantas e que isto acontece em simultâneo com um aumento da atividade de enzimas que regulam os conteúdos de ERO tanto em raízes como em folhas. ${ }^{50}$ A regulação de metabolismo redox por parte dos $\mathrm{AH}$ induz um estado fisiológico de proteção nas plantas diante do estresse hídrico. Quando os AH são aplicados em plantas de arroz submetidas a estresse hídrico, as condições fisiológicas e de homeostase redox são novamente restauradas. Isto indica um efeito protetor dos $\mathrm{AH}$ nas plantas pela diminuição dos danos ocasionados pelo aumento das ERO em plantas (Figura 6). ${ }^{51}$

A regulação do metabolismo redox nas plantas pela aplicação de SH ocorre em parte em nível intracelular. ${ }^{51} U$ ma intensa regulação da expressão gênica de aquaporinas do tonoplasto (membrana vacuolar) (TIPs) em plantas de arroz tem sido um efeito comumente observado. ${ }^{50,51} \mathrm{~A}$ aplicação de $\mathrm{AH}$ induz ao aumento de ânions superóxidos $\left(\mathrm{O}_{2}{ }^{-}\right.$ ) e peróxido de hidrogênio $\left(\mathrm{H}_{2} \mathrm{O}_{2}\right)$ nas raízes das plantas, especificamente nas regiões de elongação e diferenciação. ${ }^{51} \mathrm{~A}$ diminuição dos conteúdos de $\mathrm{O}_{2} \cdot$ e $\mathrm{H}_{2} \mathrm{O}_{2}$ são o resultado de um aumento da expressão de genes responsivos da síntese de enzimas superóxido dismutase (SOD) em nível citosólico (CuZnSOD1 e CuZnSOD2) e de peroxidases (POX1) (Figura 6). ${ }^{60}$

As evidências científicas nos mostram hoje que quando os $\mathrm{AH}$ são aplicados via radicular e em solução para as plantas, ocorre uma desfragmentação da supramolécula, ${ }^{47,52 \text {, }}$ possivelmente em regiões próximas da raiz onde o valor de $\mathrm{pH}$ pode ser inferior a 3.0. A este valor de $\mathrm{pH}$, alguns fragmentos de $\mathrm{SHs}$ podem se aglomerar na superfície radicular, causando entupimento de poros e modificando a funcionalidade da raiz. ${ }^{47,52,60}$ Estes efeitos podem ocasionar um estado de pseudoestresse ou estresse brando nas plantas que em resposta, desencadeia um sistema de sinalização através das ERO, estimulando assim tanto o crescimento radicular como a proteção das plantas diante de estresses abióticos (Figura 6). ${ }^{47,52,60,61} \mathrm{O}$ papel das ERO como moléculas sinalizadoras em plantas e seu papel determinantes na emissão de raízes já tem sido relatado amplamente na literatura ${ }^{53,56}$. 


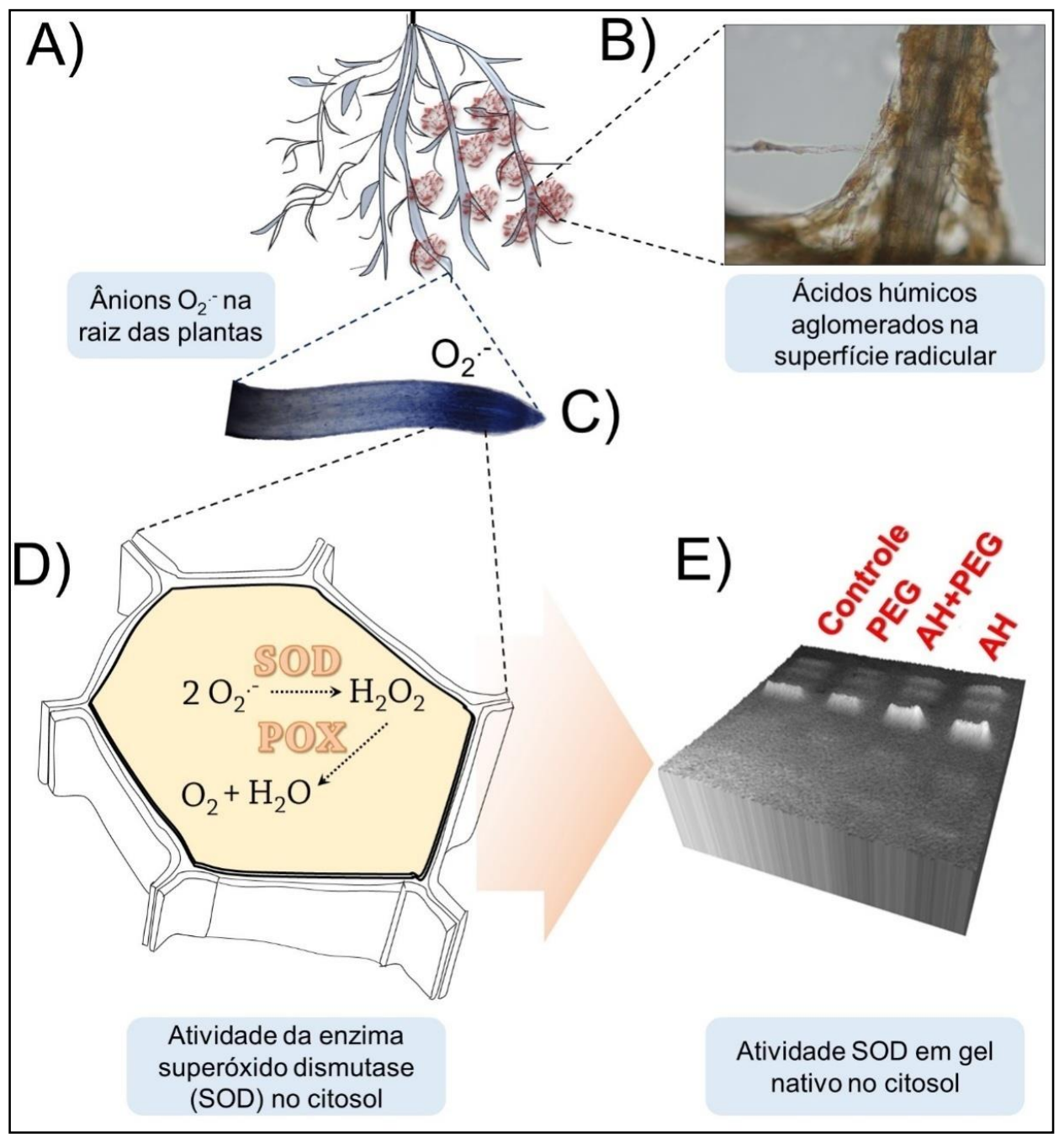

Figura 6. Esquema conceitual mostrando a relação hipotética entre a aglomeração dos ácidos húmicos em raízes de plantas (A, B) (Berbara e García, 2014), gerando uma regulação de ERO nas raízes das plantas (C) (García et al., 2016), especificamente no citosol (D) (García et al., 2016) aumentando a atividade das SOD (García et al., 2016)

\section{Relação da Estrutura das Substâncias Húmicas com as suas Funções em Nível Radicular}

A impossibilidade de estabelecer um modelo químico húmico não tem constituído um obstáculo para conhecer o tipo de função que cada estrutura húmica realiza. 0 acesso à relação estrutura-propriedade-função pode ser facilitado mediante a aplicação de técnicas espectroscópicas (FTIR, ${ }^{13} \mathrm{C}$ RMN, etc.) que permitam a obtenção das características estruturais das supramoléculas húmicas. ${ }^{31,62}$ As propriedades químicas extraídas da espectroscopia podem ser obtidas por meio de procedimentos matemáticos integrando as regiões espectrais e mais especificamente por meio da utilização de análise quimiométrica. ${ }^{31,62} \mathrm{~A}$ função de cada estrutura na supramolécula pode ser acessada também a partir de análise quimiométricas utilizando PCA (Principal componentes analisys), PLS (Partial Least Square), PCR (Principal Component Regretion).

Esta abordagem metodológica tem permitido desemaranhar a participação dos diferentes fragmentos húmicos dentro da supramolécula no crescimento radicular das plantas. ${ }^{11,12} \mathrm{~A}$ aplicação de PLS em estudos de relação estrutura-função, mostrou que em 
plantas de milho, a emissão de raízes pela aplicação de $\mathrm{AH}$ responde à presença estrutural de fragmentos polares $\left(\mathrm{C}_{\text {Akyl }} \mathrm{O}\right.$ e $\mathrm{C}_{\text {Alkyl}} \mathrm{O}, \mathrm{N}$ ) e ao índice de hidrofobicidade como uma propriedades determinante. ${ }^{62}$ Mediante $P C R$, foi possível ampliar este entendimento e mostrar que as estruturas methoxil, aril, O-aril e carboxil definem a indução de raízes laterais em plantas. ${ }^{62}$

O grupo de pesquisa do LQBS tem estabelecido uma ordem de compreensão mais extensa para este tipo de estudo. A nossa interpretação entende a supramolécula húmica como uma entidade com um padrão de características estruturais próprias que geram propriedades químicas capazes de definir o tipo de função (bioatividade) que cada domínio organizacional/estrutural desempenha.

O proposto em nossos estudos é a utilização em um primeiro momento de modelos de PCA a partir do carregamento quimiométrico dos espectros puros para estabelecer padrões de semelhanças estrutural entre as $\mathrm{SH}$. Isto permite eliminar outliers estruturais produto de processos ineficazes de isolamento, purificação e baixa resolução espectral. Uma vez aceito o melhor modelo por PCA é possível então carregar espectros puros para a obtenção de CRM que oferecem informações qualitativas e quantitativas sobre os componentes espectrais. ${ }^{63}$ Finalmente, as análises de PCR ou PLS permitem mostrar e validar a relação entre as estruturas e a atividade pelo retorno analítico de um padrão espectral capaz de ser interpretado.

Com esta lógica de interpretação, a bioatividade em plantas, especificamente sobre o crescimento radicular de aproximadamente 37 frações húmicas foi testada. ${ }^{31} \mathrm{~A}$ CRM permitiu comprovar padrões espectrais de dois componentes determinantes na estrutura dos $\mathrm{AH}$, um componente hidrofóbico composto por estruturas predominantemente apolares $\left(\mathrm{C}_{\text {Alkyl}}-\mathrm{H}, \mathrm{R}, \mathrm{C}_{\mathrm{Arm}}-\mathrm{H}, \mathrm{R}\right)$ e um componente hidrofílico composto por estruturas $\mathrm{C}_{\text {Alkyl }} \mathrm{O}, \mathrm{N}$, $\mathrm{C}_{\text {Alkyl}}-\mathrm{O}, \mathrm{C}_{\text {Alkyl}}-$ di-O, $\mathrm{C}_{\text {Arm }}-\mathrm{O}, \mathrm{N}$ e - $\mathrm{COOH}$. Estas evidências confirmam o padrão estrutural preservado das $\mathrm{SH}$ como entidade estrutural supramolecular. ${ }^{31}$ Aanálise de PCR mostra que o padrão espectral (estruturas) responsável pela emissão de raízes nas SH íntegras está composto por carbonos lábeis $\left(\mathrm{C}_{\text {Alkyl }} \mathrm{O}, \mathrm{N}\right.$, $\mathrm{C}_{\text {Alkyl-O}} \mathrm{O}, \mathrm{C}_{\text {Alkyl-di-O }}, \mathrm{C}_{\text {Arm }}-\mathrm{O}, \mathrm{N}$ e $-\mathrm{COOH}$ ) enquanto nos $A H, O$ padrão espectral responsável está composto por estruturas mais recalcitrantes $\left(\mathrm{C}_{\text {Alkyl }}-\mathrm{H}, \mathrm{R}, \mathrm{C}_{\mathrm{Arm}}-\mathrm{H}, \mathrm{R}\right)$ e $\mathrm{COOH}$. Como pode ser observado, cada padrão estrutural relacionado com a bioatividade (crescimento radicular) coincide com o padrão espectral obtido nos componentes de maior peso na CRM.

Isto significa que tem sido possível caracterizar as substâncias húmicas, obter informação estrutural, quantificar e extrair as propriedades químicas mais específicas e fornecidas mediante análises dos espectros puros e não a partir de manipulação espectral como por exemplo, índices calculados pela integração dos picos, e ao mesmo tempo relacionar estas propriedades com a sua função. ${ }^{31}$

Uma questão altamente inédita vista a partir da utilização de nossa metodologia de acesso à relação estrutura-atividade, é a visualização destas moléculas húmicas agindo de forma diferenciada segundo as suas características estruturais e domínios predominantes no crescimento radicular, porém, estes padrões estruturais em conjunto representam o espectro total e íntegro da entidade molecular húmica como um todo. Estas podem ser comprovações de um comportamento supramolecular das $\mathrm{SHs}$ (Figura 7). 


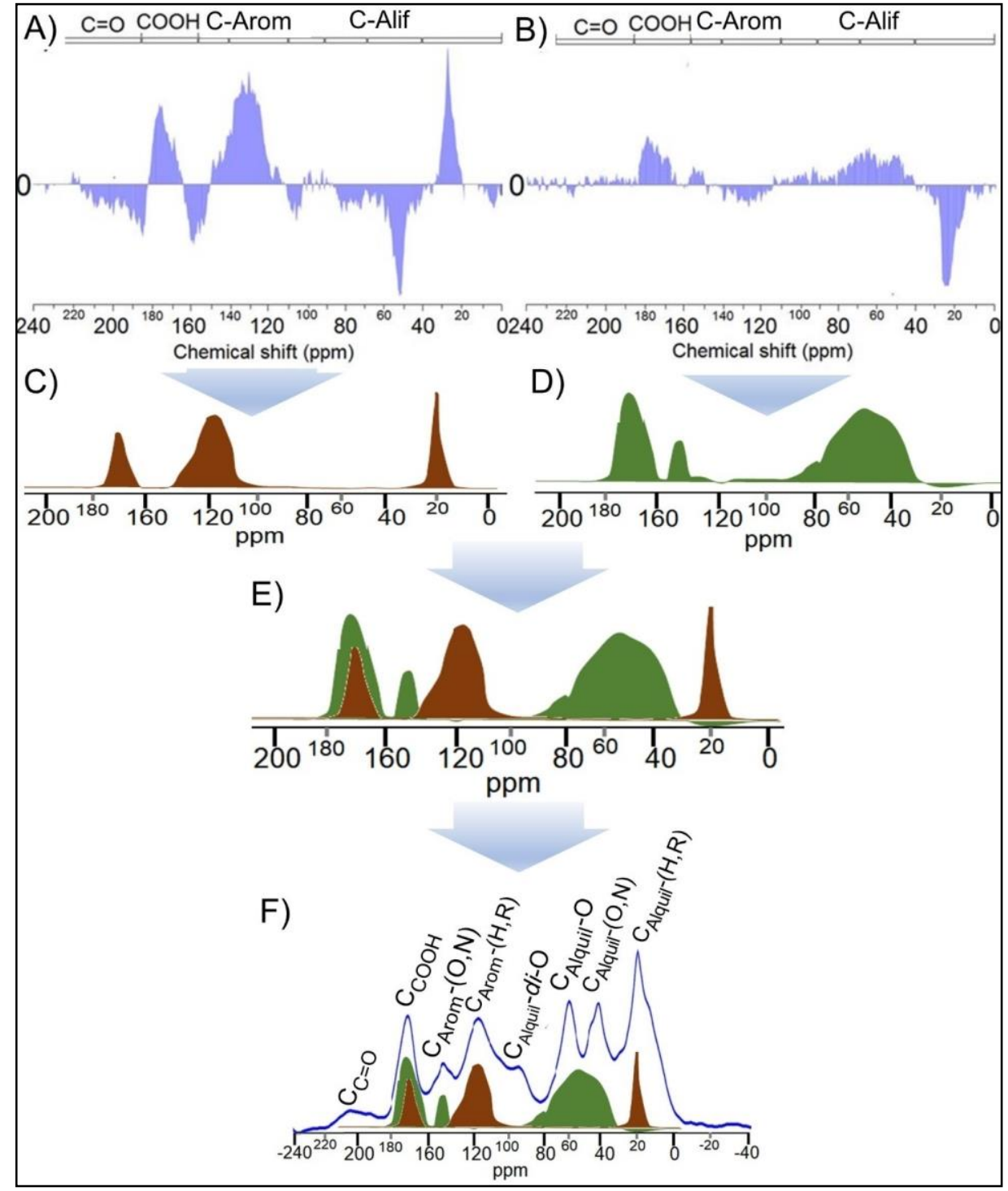

Figura 7. Análises de PCR mostrando a relação estrutural dos AH e SHs com o crescimento radicular (A, B). Extração esquemática das estruturas que positivamente se relacionam com o crescimento radicular em plantas para $\mathrm{AH}$ e $\mathrm{SHs}(\mathrm{C}, \mathrm{D})$. União esquemática das estruturas que positivamente se relacionam com o crescimento radicular em plantas (E). Sobreposição do padrão espectral médio das SHs nas extrações estruturais obtidas mediante PCR que mostra a integração supramolecular húmica regulando o crescimento radicular (García et al., 2016) ${ }^{31}$

\section{Conclusões}

O grupo de compostos presentes no solo, águas, sedimento e ar, denominados como SHs possui um padrão estrutural aplicável a diferentes tipos de origem quando isoladas de seu meio natural. A heterogeneidade estrutural, composicional e organizacional, são características que podem ser visualizadas, obtidas e quantificadas mediante técnicas de caracterização espectroscópicas aplicadas a todos os grupos de substâncias já conhecidas. Uma revisão rápida destas características é suficiente para entender que a estrutura deste grupo de compostos justifica suas funções, principalmente em solos de clima tropical. Por tanto, a impossibilidade de compreender a forma em que uma estrutura tão heterogênea do ponto de vista estrutural e termodinâmico se forma e como ela evolui e interage com o resto dos componentes do 
solo, não é suficiente para negar a sua existência como uma entidade químicoestrutural e funcional que se desenvolve e evolui de forma dinâmica em um entorno altamente complexo. A humificação então, deve ser visto como um processo que responde a um caminho cinético e termodinâmico que rege a formação das SHs segundo o entorno onde ele ocorre, por tanto, isto determinará em grande medida a quantidade dos componentes presentes na supramolécula húmica. A supramolecularidade oferece um conceito onde cabe o entendimento da organização estrutural húmica e suas funções. A partir disto temos observado como acontece a interação das SHs e as raízes de plantas e como ela regula o funcionamento da raiz e a percepção de um estado fisiológico de pseudoestresse ou estresse em plantas. Enquanto as SHs satisfazem o pré-requisito causal da relação estrutura-propriedadefunção, elas devem ser claramente tratadas como uma entidade estrutural com comportamento próprio.

\section{Agradecimentos}

Os autores agradecem ao CPGACS-PROEX, à FAPERJ pelas bolsas de incentivo à pesquisa, a CNPq pelo apoio e fomento e CAPES pelo incentivo $e$ as bolsas que permitem o andamento das pesquisas nos laboratórios da UFRRJ.

\section{Referências Bibliográficas}

${ }^{1}$ Wallerius, J. Em Agriculturae Fundamenta Chemica. Istoriyaagrikul'tury. Izd. Akad. Nauk. SSSR, 1761. [Link]

${ }^{2}$ Waksman, S. A. Em Humus origin, chemical composition, and importance in nature; Williams \& Wilkins: Baltimore, 1936. [CrossRef]
${ }^{3}$ Kononova, M. M. Em Soil organic matter: its nature, its role in soil formation and in soil fertility; Pergamon Press: Oxford, 1961. [Link]

${ }^{4}$ Kononova, M. M. Em Soil organic matter: its nature, its role in soil formation and in soil fertility, 2nd ed. Pergamon Press: Oxford, 1966. [Link]

${ }^{5}$ Russell, E. W. Em Soil conditions and plant growth, 10th ed. Longman: London, 1973. [Link].

${ }^{6}$ Orlov, D. S. Em Humus acids of soils. Russian translations Series 35. A. A; Balkema: Rotterdam, 1985. [CrossRef]

${ }^{7}$ Stevenson, F. J. Em Humus chemistry; genesis, composition, reactions. Wiley: New York, 1982. [CrossRef]

${ }^{8}$ Stevenson, F. J. Em Humus chemistry; genesis, composition, reactions, 2 nd ed. Wiley: New York, 1994. [CrossRef]

${ }^{9}$ Schulten, H. R.; Schnitzer, M. A.State of the art structural concept for humic substances. Naturwissenschaften 1993, 80, 30. [CrossRef]

${ }^{10}$ Hayes, M. H. B. Em Evolution of concepts of environmental natural nonliving organic matter; Senesi, N.; Xing, B.; Huang, P.M., (eds); John Wiley \& Sons: New York, 2009. [CrossRef]

${ }_{11}$ Piccolo, A. The supramolecular structure of humic substances. Soil Science 2001, 166, 832. [CrossRef]

12 Piccolo, A. The supramolecular structure of humic substances: a novel understanding of humus chemistry and implications in soil science. Advance Agronomy 2002, 75, 134. [CrossRef]

${ }^{13}$ Simpson, A. J.; Song, G.; Smith, E.; Lam, B.; Novotny, E. H.; Hayes, M. H. B. Unravelling the structural components of soil humin by use of solution-state nuclear magnetic resonance spectroscopy. Environment Science Technology 2007, 41, 883. [CrossRef]

${ }^{14}$ Nebbioso, A.; Piccolo, A. Advances in humeomics: enhanced structural identification of humic molecules after size fractionation of a soil humic acid. Analytica 
Chimica Acta 2012, 77, 720. [CrossRef] [PubMed]

${ }^{15}$ Nebbioso, A.; Piccolo, A. Basis of a humeomics science: chemical fractionation and molecular characterization of humic biosuprastructures. Biomacromolecules 2011, 1187, 12. [CrossRef] [PubMed]

${ }^{16}$ Piccolo, A. In memoriam Prof. F. J. Stevenson and the Question of humic substances in soil. Chemical and Biological Technologies in Agriculture 2016, 3, 23. [CrossRef]

${ }^{17}$ Nardi, S.; Pizzeghello, D.; Muscolo, A.; Vianello, A. Physiological effects of humic substances on higher plants. Soil Biology and Biochemistry 2002, 1527, 34. [CrossRef]

${ }^{18}$ Chen, Y.; De Nobili, M.; Aviad, T. Em Stimulatory Effects of Humic. Soil organic matter in sustainable agriculture 2004, 25, 59. [CrossRef]

${ }^{19}$ Piccolo, A. Humic substances in terrestrial ecosystems. Elsevier: Amsterdã, 1996. [CrossRef]

${ }^{20}$ Piccolo, A.; Mbagwu, J. S. C. Effects of different organic waste amendments on soil microaggregates stability and molecular sizes of humic substances. Plant and Soil 1990, 123, 37. [CrossRef]

${ }^{21}$ Volikov, A. B.; Kholodov, V. A.; Kulikova, N. A.; Philippova, O. I.; Ponomarenko, S. A.; Lasareva, E. V.; Perminova. I. V. Silanized humic substances act as hydrophobic modifiers of soil separates inducing formation of water-stable aggregates insoils. Catena 2016, 137, 236. [CrossRef]

${ }^{22}$ Scott, D. T.; McKnight, D. M.; Blunt-Harris, E. L.; Kolesar, S. E.; Lovley, D. R. Quinone moieties act as electron acceptors in the reduction of humic substances by humicsreducing microorganisms. Environmental Science \& Technology 1998, 2984, 32. [CrossRef]

${ }^{23}$ Piccolo, A.; Stevenson, F.J. Infrared spectra of $\mathrm{Cu}^{2+}, \mathrm{Pb}^{2+}$ and $\mathrm{Ca}^{2+}$ complexes of soil humic substances. Geoderma 1982, 195,27. [CrossRef]
${ }^{24}$ Tan, K. H. Em Humic matter in soil and the environment: principles and controversies. CRC Press: Boca Raton, 2014. [CrossRef]

${ }^{25}$ Tan, K. H. Em Andosols (in Indonesian). Syllabus of Lectures, Grad. School, University of North Sumatra, Medan, Indonesia, 1998.

${ }^{26}$ Vaughan, D.; Malcolm, R. E. Em Influence of humic substances on growth and physiological processes. Springer Netherlands: Heidelberg, 1985. [CrossRef]

${ }^{27}$ Hernando, V.; Ortega, B. C.; Fortun, C. Em Study of the action of two types of humic acid on the maize plant. Soil Organic Matter Studies, 1977. [Link]

${ }^{28}$ Elgala, A. M.; Metwally, A. I.; Khalil, R. A. The effect of humic acid and $\mathrm{Na}_{2}$ EDDHA on the uptake of $\mathrm{Cu}, \mathrm{Fe}$, and $\mathrm{Zn}$ by barley in sand culture. Plant and Soil 1978, 41, 49. [CrossRef]

${ }^{29}$ Dobbss, L. B.; Medici, L. O.; Peres, L. E. P.; Pino-Nunes, L. E.; Rumjanek, V. M.; Façanha, A. R.; Canellas, L. P. Changes in root development of Arabidopsis promoted by organic matter from oxisols. Annals of Applied Biology 2007, 199, 151. [CrossRef]

${ }^{30}$ Tavares, O. C. H.; Doutorado em Fitotecnia. Universidade Federal Rural do Rio de Janeiro, Brasil, 2014. [Link]

${ }^{31}$ García, A. C.; de Souza, L. G. A.; Pereira, M. G.; Castro, R. N.; García-Mina, J. M.; Zonta, E.; Berbara, R. L. L. Structure-Property-Function Relationship in Humic Substances to Explain the Biological Activity in Plants. Scientific reports 2016, 6, 20798. [CrossRef] [PubMed]

32 Canellas, L. P.; Olivares, F. L.; OkorokovaFaçanha, A. L.; Façanha, A. R. Humic acids isolated from earthworm compost enhance root elongation, lateral root emergence, and plasma membrane $\mathrm{H}^{+}$-ATPase activity in maize roots. Plant physiology 2002, 1951, 130. [CrossRef] [PubMed]

${ }^{33}$ Van de Venter, H. A.; Furter, M.; Dekker, J.; Cronje, I. J. Stimulation of seedling root growth by coal-derived sodium humate. Plant and soil 1991, 17, 138. [CrossRef]

${ }^{34}$ Pinton, R.; Cesco, S.; Santi, S.; Agnolon, F.; Varanini, Z. Water-extractable humic substances enhance iron deficiency responses 
by Fe-deficient cucumber plants. Plant and Soil 1999, 145, 210. [CrossRef]

35 Jannin, L.; Arkoun, M.; Ourry, A.; Laîné, P.; Goux, D.; Garnica, M.; Houdusse, F. Microarray analysis of humic acid effects on Brassica napus growth: involvement of $\mathrm{N}, \mathrm{C}$ and S metabolisms. Plant and soil 2012, 297, 359. [CrossRef]

${ }^{36}$ Schmidt, W.; Santi, S.; Pinton, R.; Varanini, Z. Water-extractable humic substances alter root development and epidermal cell pattern in Arabidopsis. Plant and soil 2007, 259, 300. [CrossRef]

${ }^{37}$ Tavares, O. C. H.; Santos, L. A.; Ferreira, L. M.; Sperandio, M. V. L.; da Rocha, J. G.; García, A. C.; Fernandes, M. S. Humic acid differentially improves nitrate kinetics under low-and high-affinity systems and alters the expression of plasma membrane $\mathrm{H}^{+}$-ATPases and nitrate transporters in rice. Annals of Applied Biology 2017, 89, 170. [CrossRef]

${ }^{38}$ Solos, E. Sistema brasileiro de classificação de solos. Centro Nacional de Pesquisa de Solos: Rio de Janeiro, 2013. [Link]

${ }^{39}$ Schmidt, M. W.; Torn, M. S.; Abiven, S.; Dittmar, T.; Guggenberger, G.; Janssens, I. A.; Nannipieri, P. Persistence of soil organic matter as an ecosystem property. Nature 2011, 478, 49. [CrossRef] [PubMed]

${ }^{40}$ Lehmann, J.; Kleber, M. The contentious nature of soil organic matter. Nature 2015, 528, 60. [CrossRef] [PubMed]

${ }^{41}$ Chen, C.; Leinweber, P.; Eckhardt, K. U.; Sparks, D. L. The Composition and Stability of Clay-Associated Organic Matter along a Soil Profile. Soil Systems 2018, 2, 16. [CrossRef]

${ }^{42}$ Piccolo, A.; Spaccini, R.; Drosos, M.; Vinci, G.; Cozzolino, V. Em The Molecular Composition of Humus Carbon: Recalcitrance and Reactivity in Soils. Academic Press: Cambridge, 2018, cap 4. [CrossRef]

\section{${ }^{43}$ https://humic-substances.org. CrossRef}

${ }^{44}$ Keeler, C.; Kelly, E. F.; Maciel, G. E. Chemical-structural information from solidstate ${ }^{13} \mathrm{C}$ NMR studies of a suite of humic materials from a lower montane forest soil,
Colorado, USA. Geoderma 2006, 124, 130. CrossRef

${ }^{45}$ Fischer, T. Humic supramolecular structures have polar surfaces and unpolar cores in native soil. Chemosphere 2017, 437, 183. [CrossRef] [PubMed]

${ }^{46}$ Asli, S.; Neumann, P. M. Rhizosphere humic acid interacts with root cell walls to reduce hydraulic conductivity and plant development. Plant and Soil 2010, 313, 336. [CrossRef]

${ }^{47}$ Olaetxea, M.; Mora, V.; Bacaicoa, E.; Baigorri, R.; Garnica, M.; Fuentes, M.; Ederra, I. ABA-regulation of root hydraulic conductivity and aquaporin gene-expression is crucial to the plant shoot rise caused by rhizosphere humic acids. Plantphysiology 2015, 169, 596. [CrossRef] [PubMed]

48 Ojwang', L. M.; Cook, R. L. Environmental conditions that influence the ability of humic acids to induce permeability in model biomembranes. Environmental Science \& Technology 2013, 8280, 47. [CrossRef] [PubMed]

${ }^{49}$ Kulikova, N. A.; Abroskin, D. P.; Badun, G. A.; Chernysheva, M. G.; Korobkov, V. I.; Beer, A. S.; Perminova, I. V. Label distribution in tissues of wheat seedlings cultivated with tritiumlabeled leonardite humic acid. Scientific Reports 2016, 6, 28869. [CrossRef] [PubMed]

${ }^{50}$ García, A. C.; Santos, L. A.; Izquierdo, F. G.; Sperandio, M. V. L.; Castro, R. N.; Berbara, R. L. L. Vermicompost humic acids as an ecological pathway to protect rice plant against oxidative stress. Ecological Engineering 2012, 203, 47. [CrossRef]

${ }^{51}$ García, A. C.; Santos, L. A.; Izquierdo, F. G.; Rumjanek, V. M.; Castro, R. N.; dos Santos, F. S.; Berbara, R. L. L. Potentialities of vermicompost humic acids to alleviate water stress in rice plants (Oryza sativa L.). Journal of Geochemical Exploration 2014, 48, 136. [CrossRef]

52 Berbara, R. L.; García, A. C. Em Humic substances and plant defense metabolism. Springer: New York, 2014. [CrossRef] 
${ }^{53}$ Mittler, R.; Vanderauwera, S.; Suzuki, N.; Miller, G.; Tognetti, V. B., Vandepoele, K.; Van Breusegem, $F$. ROS signaling: the new wave? Trends in plant science 2011, 300, 6. CrossRefPubMed

${ }^{54}$ Suzuki, N.; Koussevitzky, S. H. A. I.; Mittler, R. O. N.; Miller, G. A. D. ROS and redox signalling in the response of plants to abiotic stress. Plant, Cell \& Environment 2012, 259, 35. [CrossRef] [PubMed]

${ }^{55}$ Baxter, A.; Mittler, R.; Suzuki, N. ROS as key players in plant stress signalling. Journal of Experimental Botany 2013, 65, 1229. [CrossRef] [PubMed]

${ }^{56}$ Foreman, J.; Demidchik, V.; Bothwell, J. H.; Mylona, P.; Miedema, H.; Torres, M. A.; Davies, J. M. Reactive oxygen species produced by NADPH oxidase regulate plant cell growth. Nature 2003, 442, 27. [CrossRef] [PubMed]

${ }^{57}$ Demidchik, V.; Shabala, S. N.; Davies, J. M. Spatial variation in $\mathrm{H}_{2} \mathrm{O}_{2}$ response of Arabidopsis thaliana root epidermal $\mathrm{Ca}^{2+}$ flux and plasma membrane $\mathrm{Ca}^{2+}$ channels. The Plant Journal 2007, 377, 49. [CrossRef] [PubMed]

${ }^{58}$ Demidchik, V.; Shang, Z.; Shin, R.; Thompson, E.; Rubio, L.; Laohavisit, A.; Schachtman, D. P. Plant extracellular ATP signalling by plasma membrane NADPH oxidase and $\mathrm{Ca}^{2+}$ channels. The Plant Journal 2009, 903, 58. [CrossRef] [PubMed]
${ }^{59}$ Rose, M. T.; Patti, A. F.; Little, K. R.; Brown, A. L.; Jackson, W. R.; Cavagnaro, T. R. A. Em Meta-analysis and review of plant-growth response to humic substances: practical implications for agriculture; Academic Press: Cambridge, 2014, cap 2. [CrossRef]

${ }^{60}$ García, A. C.; Santos, L. A.; de Souza, L. G. A.; Tavares, O. C. H.; Zonta, E.; Gomes, E. T. M.; Berbara, R. L. L. Vermicompost humic acids modulate the accumulation and metabolism of ROS in rice plants. Journal of Plant Physiology 2016, 56, 192. [CrossRef] [PubMed]

${ }^{61}$ Aguiar, N. O.; Medici, L. O.; Olivares, F. L.; Dobbss, L. B.; Torres-Netto, A.; Silva, S. F.; Canellas, L. P. Metabolic profile and antioxidant responses during drought stress recovery in sugarcane treated with humic acids and endophytic diazotrophic bacteria. Annals of Applied Biology 2016, 203, 2. [CrossRef]

${ }^{62}$ Aguiar, N. O.; Novotny, E. H.; Oliveira, A. L.; Rumjanek, V. M.; Olivares, F. L.; Canellas, L. P. Prediction of humic acids bioactivity using spectroscopy and multivariate analysis. Journal of Geochemical Exploration 2013, 95, 129. [CrossRef]

${ }^{63}$ Esbensen, K. H.; Guyot, D.; Westad, F.; Houmoller, L. P. Em Multivariate data analysis: in practice: an introduction to multivariate data analysis and experimental design, Aalborg University: Esbjerg, 2002, cap 1. [Link] 